\title{
Highlights of the 34th Annual Gravens Conference on the Environment of Care for the High-Risk Newborn and Satellite Conference on "Reimagining the NICU"
}

Robert D. White, MD

\section{"The 34th annual Gravens Conference was held virtually this March, bringing scientists, clinicians, and advocates together to discuss the environment of care of the high-risk newborn"}

The $34^{\text {th }}$ annual Gravens Conference was held virtually this March, bringing scientists, clinicians, and advocates together to discuss the environment of care of the high-risk newborn. As in the past, presentations focused on the biology of the newborn brain and developmentally supportive care, care and support of the baby's family, and new directions in NICU design and operation.

Biology of the Newborn Brain and Developmental Care

Dr. Regina Sullivan (NYU) reviewed infant attachment as described in both the animal and human literature. She discussed the intimate feedback mechanisms that develop between an infant and caregiver and how stressful settings can permanently affect brain structure and biochemistry. Dr. Gretchen Lawhon (Philadelphia) showed the continued influence of the environment on newborn brains as they transition from the NICU to home. Dr. Samantha Butler (Boston Children's) then described a QI project for implementing developmental care in a Cardiac ICU. Several abstracts were presented that continued to build evidence on the value of kangaroo care to both baby and parent.

Integration of the Family into NICU Care

Dr. Lee Gettler (Notre Dame) reviewed a growing body of evidence that substantive changes occur in hormone levels of new fathers and that these can be influenced by early intimate contact with their newborn infants, with a long-term impact on their commitment to parenting. DeWayne Pursley (Beth Israel Deaconess) provided extensive evidence of racial disparities in health care and how those strongly influence newborn outcomes. Julian and Shante Nixon (NICU parents, South Carolina) gave a face to these statistics, recounting their experience with inequities they experienced as African-American parents in the NICU. Betsy PiIon, founder and executive director of Hope for HIE, presented the many resources now available to families of babies with hypoxicischemic encephalopathy. Several abstract presentations described the impact of COVID restrictions on family interaction with their babies in the NICU, and we heard about a unique program that provides housing for high-risk pregnant women in a Native American population.

\section{Design and Operational Considerations in the NICU}

Two new NICUs were described; Dr. David Paul presented the NICU at Christiana Care in Newark, Delaware and Dr. John Wimmer presented the NICU at Cone Health in Greenville, NC. Both units incorporated single-family rooms and couplet care rooms into their design then did post-occupancy evaluations that showed very high acceptance of this new model of care among both families and caregivers. Dr. Whitney Gray (International WELL Building Institute) and Dr. Mardelle Shepley (Cornell) reviewed the WELL Building Standards and related them to NICU design and operation in ways that can improve air, water, light, and sound quality to the benefit of occupants and the community. Technological advances utilizing artificial intelligence in the NICU were proposed by Dr. Jim Gray and Joanna Celenza (Dartmouth), and Bridget Davern (Minnesota) with a subsequent workshop that focused on new ways to support communication with parents. A team from Lurie Childrens' (Chicago) also presented a workshop that described their program to engage families via telemedicine.

\section{"Technological advances utilizing artificial intelligence in the NICU were proposed by Dr. Jim Gray and Joanna Celenza (Dartmouth), and Bridget Davern (Minnesota) with a subsequent workshop that focused on new ways to support communication with parents."}

\section{Reimagining the NICU}

A special feature of Gravens this year was a post-conference seminar sponsored by the Sextant Foundation that brought clinicians and parents together with hospital planners and designers to imagine what the NICU of the future might look like. Several multidisciplinary teams spent one day identifying many needs, including balancing the family's need for privacy while avoiding isolation, the challenges new designs place on caregivers, and the need for developmentally appropriate stimuli for babies while simultaneously reducing noxious stimuli. There was also a desire to create additional support space for families and caregivers. A

NEONATOLOGY TODAY is interested in publishing manuscripts from Neonatologists, Fellows, NNPs and those involved in caring for neonates on case studies, research results, hospital news, meeting announcements, and other pertinent topics.

Please submit your manuscript to: LomaLindaPublishingCompany@gmail.com 
second day was focused on potential solutions, which fell into four categories:

- Creation of a "community space" at the heart of the NICU as a gathering place for families and a central staging area for caregivers, distinct from the long hallways typical in current hospital design

- Room designs that could adapt to the needs of the baby and the family, allowing a more personalized experience

- Use of technology to deliver patient information, parent education, and a home-like atmosphere

- Operational changes that enhanced family support and the environment of care for the infant

This project is ongoing; the third day of prototype development will occur in mid-May, then the prototypes will be presented at the 2022 Gravens Conference to solicit input from all attendees. After that session, suggested changes to the next edition of the Recommended Standards for NICU Design will be summarized along with subsequent proposals for changes to the FGI Guidelines that

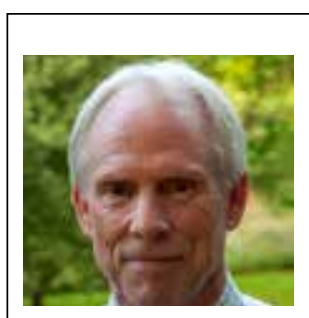

Corresponding Author

Robert D. White, MD

Director, Regional Newborn Program

Beacon Children's Hospital

615 N. Michigan St.

South Bend, IN 46601

Phone: 574-647-7141

Fax: 574-647-3672

Email: RobertWhite@pediatrix.com
"This project is ongoing; the third day of prototype development will occur in midMay, then the prototypes will be presented at the 2022 Gravens Conference to solicit input from all attendees. After that session, suggested changes to the next edition of the Recommended Standards for NICU Design will be summarized along with subsequent proposals for changes to the FGI Guidelines that are used by most states for their hospital building codes."

are used by most states for their hospital building codes.

All the 2021 Gravens presentations are available for viewing now through September 30; register at https://health.usf.edu/publichealth/chiles/gravens-conference/registration. The $35^{\text {th }}$ Gravens Conference on the Environment of the High-Risk Newborn is planned for March 9-12 in Clearwater Beach, Florida.

Disclosures: The author has no relevant disclosures

NT

\section{SHARED DECISION-MAKING}

PROTECTS PARENTS + BABIES
INFORMED PROVIDERS

Seek participation

Help explore options

A ssess preferences

$\mathrm{R}$ each a decision

Evaluate the decision

CARE DELIVERY REQUIRES

PARTNERSHIP
COVID-19

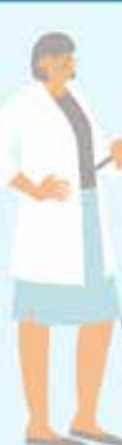

$\longrightarrow$

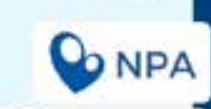

nationalperinataLorg/NPAandNANN

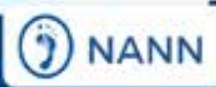

Caring for Babies and their Families: Providing Psychosocial Support to NICU Parents

7- Module Online Course in NICU Staff Education
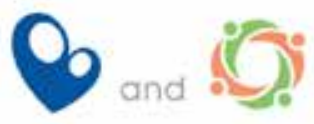

National Perinatal Association and NICU Parent Netwark

mynicunetwork.org 